\title{
KÜNTSCHER INTRAMEDULLARY REAMING AND NAIL FIXATION FOR NON-UNION OF FRACTURE OF THE FEMUR AND THE TIBIA
}

\author{
Niels Olaf Christensen, Lund, Sweden
}

Rigid stability has long been the accepted major principle for treatment of non-union of shaft fractures (Müller, Allgöwer and Willenegger 1965; Böhler 1966; Müller 1966; Küntscher 1967). Until recently, methods of gaining stability have usually combined internal fixation by osteosyntheses and external fixation by plaster or traction (Boyd, Anderson and Johnston 1966). These methods have the disadvantage of further increasing the joint stiffness and muscle atrophy which usually accompany non-union. Moreover, the fixation does not allow weightbearing, an important stimulus to fracture union. It was therefore interesting that Küntscher (Fischer 1965, Küntscher 1967) was able to improve on his method of intramedullary nail fixation by reaming the shaft to uniform diameter, thus ensuring such rigid fracture fixation that immediate joint movement and weight-bearing could be allowed even in cases of non-union (Maurath and Christ 1963).

This paper reports a consecutive series of thirty-five cases of non-union of femur or tibia, treated by the modern Küntscher method. Before operation some of these limbs were subjected to transfixation distraction for correction of shortening or mal-alignment (Küntscher 1967, Christensen 1970).

\section{MATERIAL}

During the period 1966-72 twenty femurs and fifteen tibias were operated upon (Tables I and II). The patients were young or middle aged. All the fractures were due to severe trauma, usually from traffic accidents. Two femurs and three tibias had open fractures. Six femoral fractures and three tibial fractures were comminuted. About half of the patients with femoral fractures sustained additional fractures. Most of the patients were referred from other hospitals and had had one or more operations before referral. The interval from initial injury to the operation here was from ten months to three years in most cases. The cause of non-union could not always be determined; inadequate initial internal fixation or infection was clearly responsible in some cases.

\section{METHOD OF OPERATION}

The Küntscher distractor was used before operation in four femurs and six tibias, usually for two to three weeks, to correct angulation or shortening.

Küntscher's (1967) technique was generally followed, but we found it easier to operate on the femur with the patient prone on the traction table rather than in the side position.

The guide wire, the reamer and the intramedullary nail were introduced through a 3-5 centimetre incision over the greater trochanter or the tibial tuberosity. The fracture area was opened only when necessary for passage of the guide wire or removal of internal fixation material from previous operations. The nail diameter was 14 to 18 millimetres for the femur and 11 to 14 millimetres for the tibia. Nine femurs and six tibias were nailed by the closed method.

Resection of bone in the area of non-union was never done. Grafting was done only once, two months after operation for a double fracture of the femur and then as treatment of residual rotational instability. The fibula was divided in ten of the patients with tibial fractures.

Post-operative treatment-Sufficient stability for full weight-bearing was gained in fourteen of twenty femurs and in nine of fifteen tibias. Three patients with stable femurs were restricted from walking because of infection or risk of infection. Six patients after femoral nailing 
and six after tibial nailing had restrictions because of insufficient stability associated with double fractures or other residual rotational instability. Three of these femurs were supported with a plaster; one was treated with traction because of fracture of the proximal fragment associated with the nailing procedure. Four of the six tibias with inadequate stability were supported in plasters.

\section{COMPLICATIONS}

Post-operative infection occurred in five cases, at least three of which had had infection associated with the primary treatment. Four infections cleared up without removal of the nail until the fracture was soundly healed. In one case in which the nail end impeded knee movements the nail was extracted before full fracture healing. Treatment of the infections included excision of sinuses at the fracture site, and where the nail had been introduced, removal of sequestra and administration of antibiotics both systemically and locally through an irrigation tube introduced along the nail.

\section{RESULTS}

All fractures united. Operation performed in addition to the nailing procedure was directed against infection (see above), which could be kept quiet while the pseudarthrosis healed, but generally not eliminated until the nail was removed. After that time no flare-up of infection was observed. In one case, a grafting procedure was performed two months after nailing of a double femoral pseudarthrosis. Illustrative radiographs are reproduced in Figures 1 to 10 .

\section{DISCUSSION}

The method of reaming to secure stable intramedullary nail fixation has been used by Küntscher for at least fifteen years (Fischer 1965) but seems to have won little response outside Germany until recently (Böhler 1966, Laurent and Langenskiöld 1967). One explanation may be the experience of failures after nailing without reaming (Palmer 1951, Koslowski and Weller 1962). For example, nine of our patients with non-union had primarily been treated with simple Küntscher nailing, five with Rush pins. Another reason may be reluctance to apply such radical treatment of the medullary cavity, the consequences of which have been demonstrated in animal experiments (Danckwardt-Lillieström 1969). There is, however, no clinical evidence that reaming has any adverse effect on the healing of fractures. As regards the soft tissues the method is considerably less traumatic than other open procedures.

If the Küntscher procedure is used only in cases of mid-shaft fractures with good softtissue coverage and without infection, few problems are likely to arise. In this series the indications were widened to include previously infected cases (MacAusland and Eaton 1963), double fractures, shortened fractures, and fractures relatively close to the hip, knee or ankle joints. In these cases we found it necessary to modify the treatment before and after the operation to counteract shortening or infection and in some cases to provide additional stability by external fixation with plaster, particularly in patients with severe osteoporosis. Provided these individual problems are adequately handled, the Küntscher method compares favourably with earlier methods. However, the operation may demand considerable technical skill and patience (Koslowski and Weller 1962, Laurent and Langenskiöld 1967). Undoubtedly experience facilitates a successful operation. It is necessary to be fully acquainted with the technique and the details of the instruments: a complete set of nails in all available lengths and diameters must be at hand.

The capacity for remodelling in non-union is astounding (Böhler 1966, Küntscher 1967). After rigid fixation and resumed function of the limb, healing was observed to proceed without additional stimulating measures even in severely sclerotic bone. Gaps were bridged and remodelling according to Wolff's Law was observed. Old "elephant foot" type pseudarthroses gave better fixation of the nail and healing seemed to proceed faster than in cases with lack of reaction in the fracture area and with osteoporosis.

VOL. 55 B, NO. 2, MAY 1973 


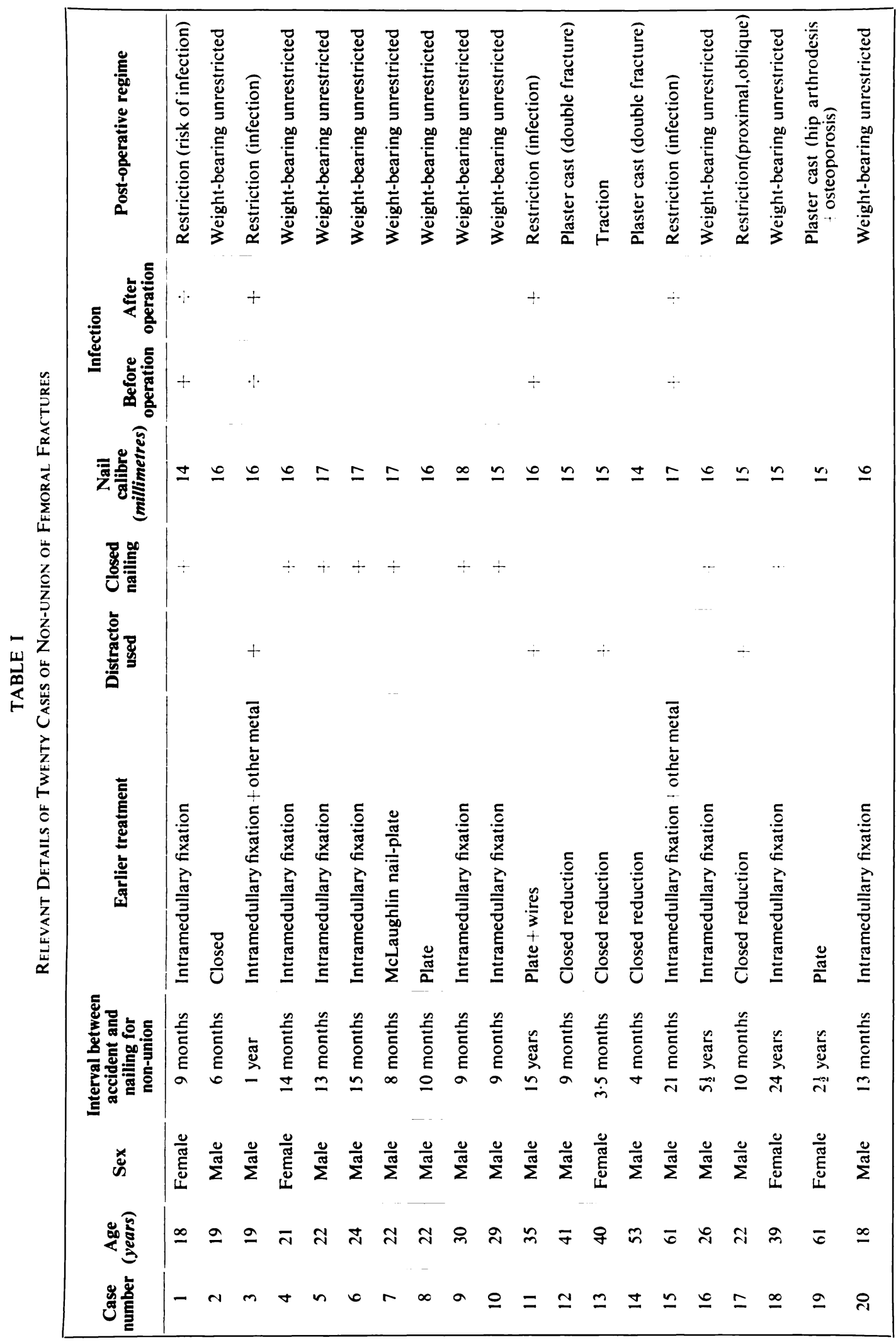

THE JOURNAL OF BONE AND JOINT SURGERY 
KÜNTSCHER INTRAMEDULLARY REAMING AND NAIL FIXATION FOR NON-UNION OF FRACTURE 315

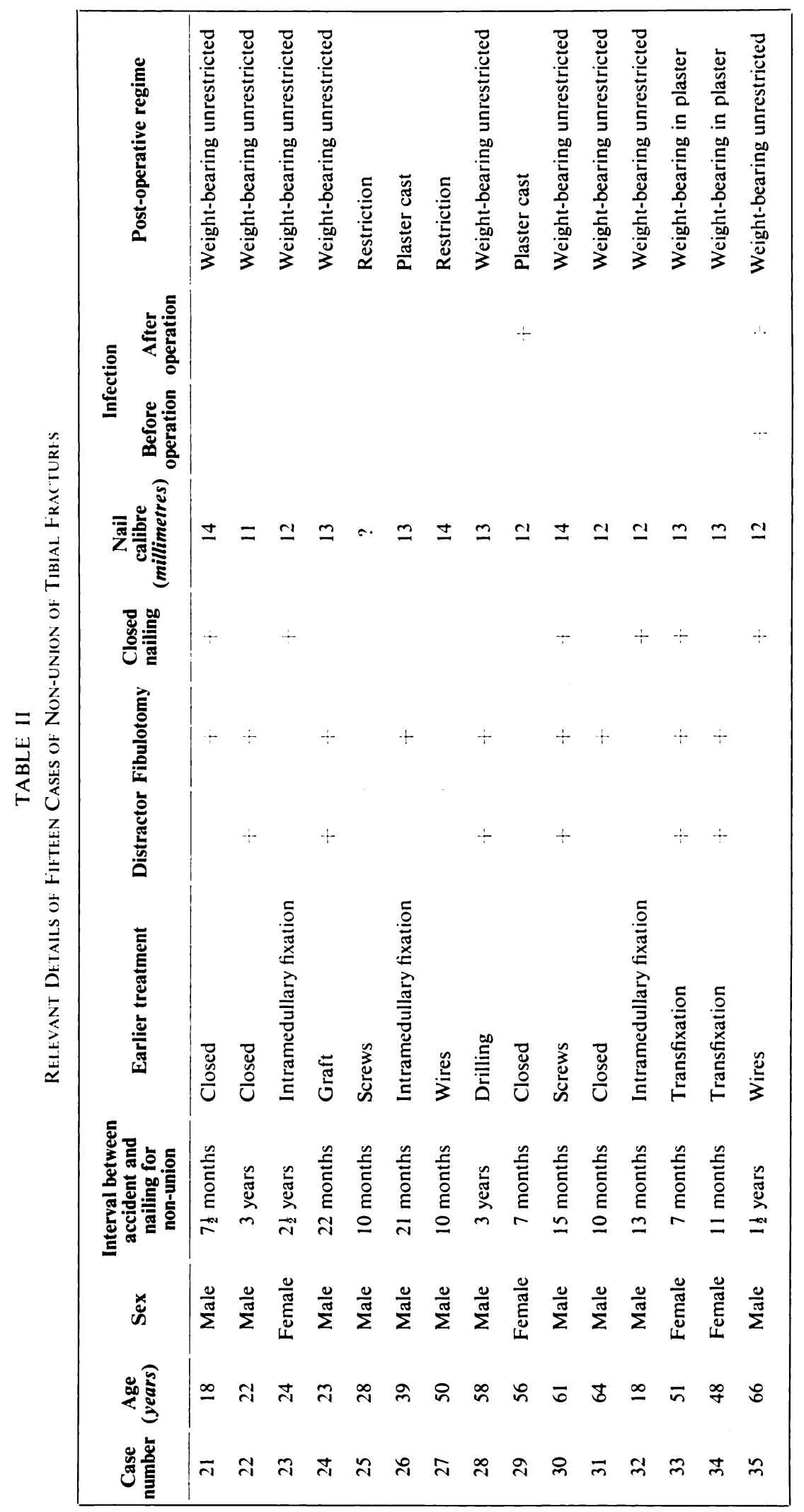

VI)L. 55 B, NO. 2, MAY 1973 


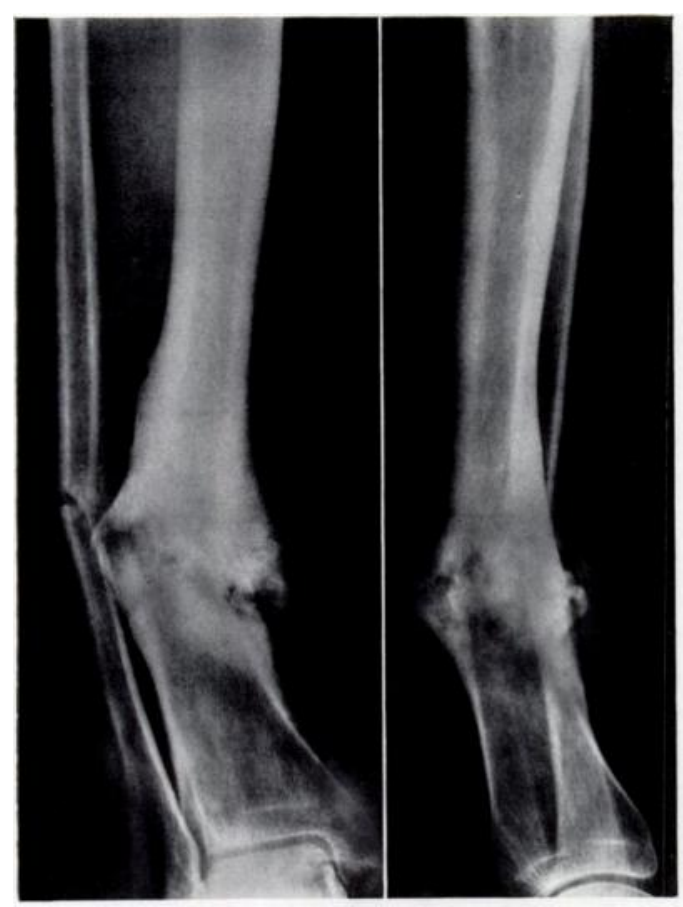

Fig. 1

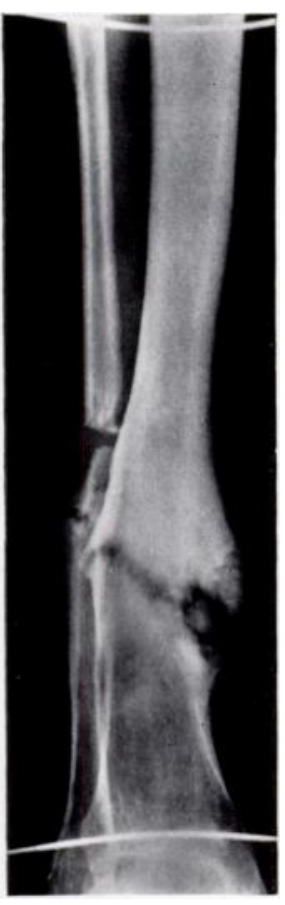

FIG. 2

Case 30. Figure 1-Non-union fifteen months after injury in a man aged 61 . Figure 2-After treatment in distractor.

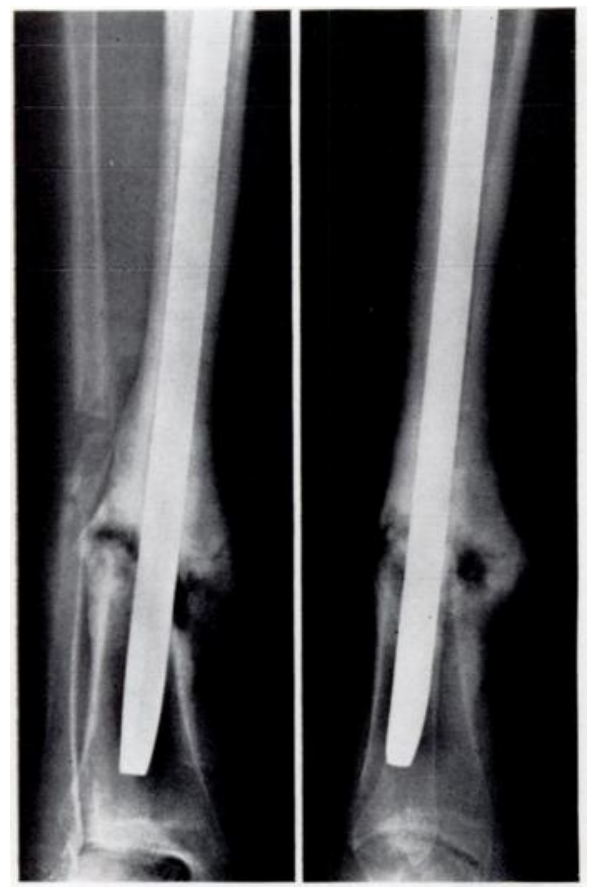

Fig. 3

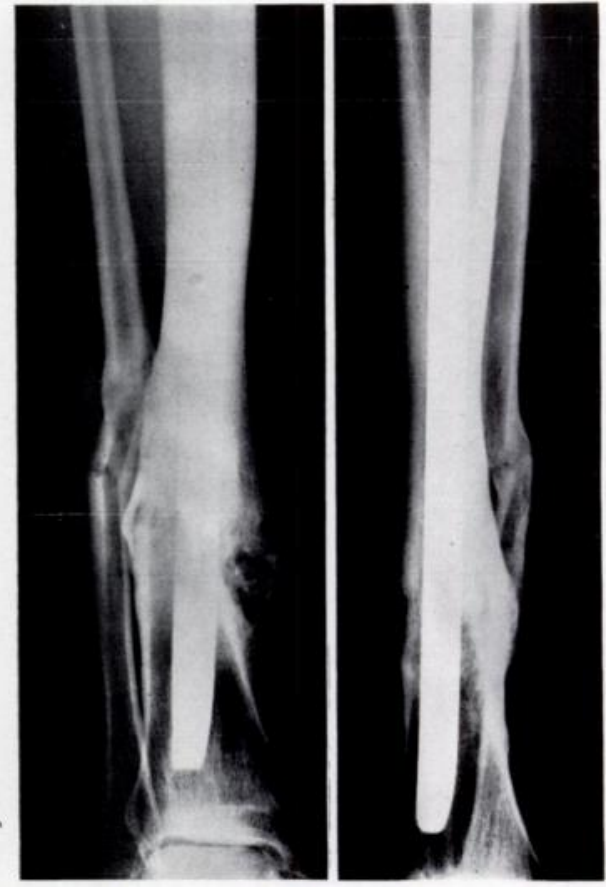

Fig. 4

Case 30. Figure 3-Radiograph soon after operation. Figure 4-Radiograph one year after operation. 


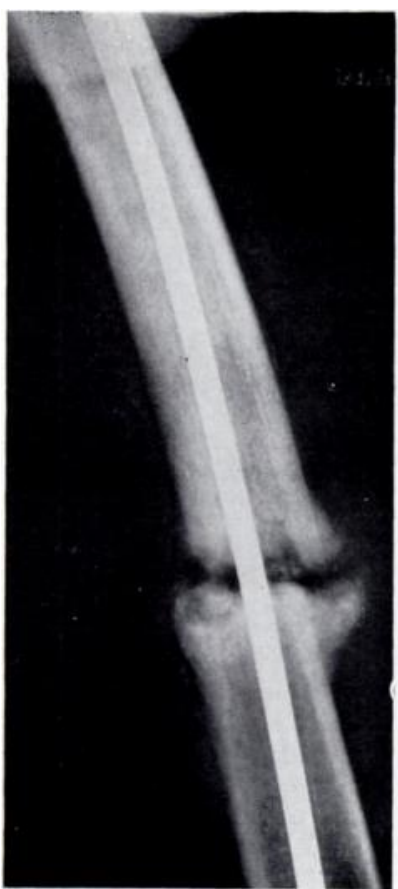

FIG. 5

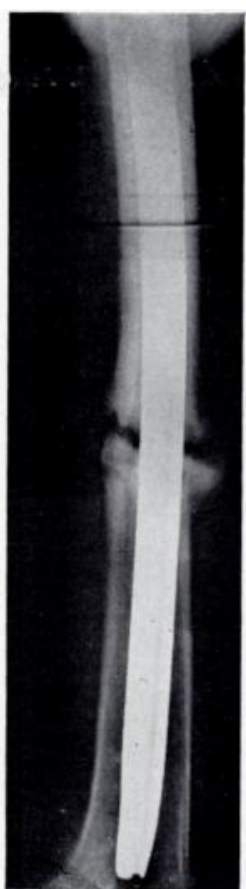

FIG. 6

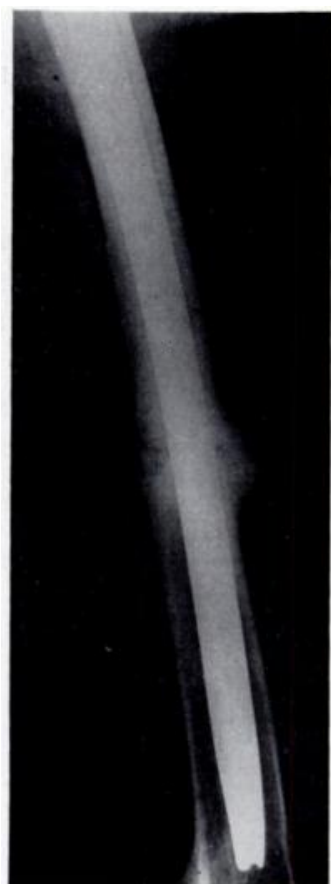

FIG. 7

Case 9. Figure 5-Non-union of femoral fracture nine months after injury in a man aged 30. Figure 6-Radiograph soon after operation. Figure 7-Radiograph seven months after operation.

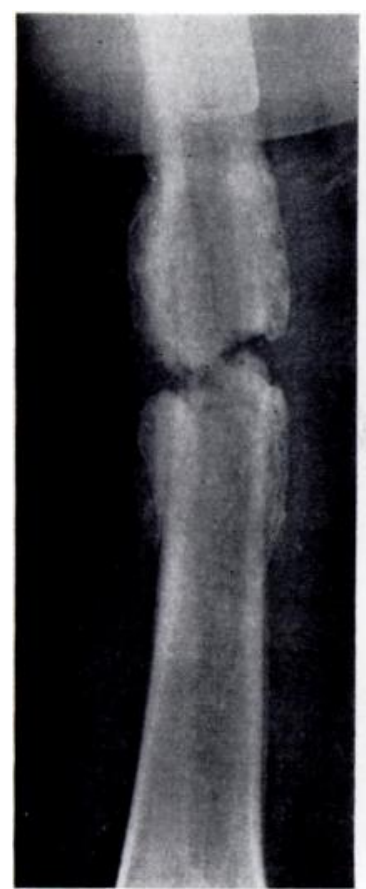

FIG. 8

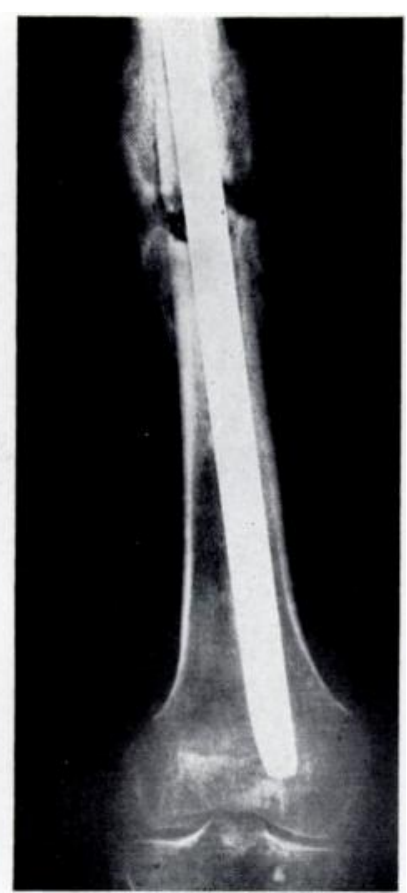

FIG. 9

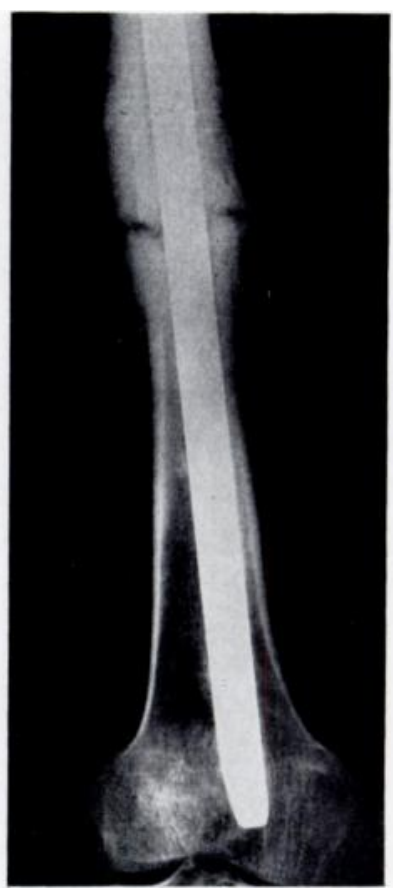

Fig. 10

Case 1. Figure 8-Non-union of femoral fracture eight months after injury in a woman aged 18. Infection under control. Figure 9-Radiograph soon after operation. Figure 10-Five months after operation showing the gap partly filled. There was no recurrence of infection after operation.

VOL. 55 B, NO. 2, MAY 1973

D 


\section{SUMMARY}

1. The Küntscher method of intramedullary reaming and nail fixation was applied to thirtyfive cases of non-union of the lower extremity, twenty femurs and fifteen tibias. A bone graft was generally not used.

2. Most of the patients were allowed to bear weight and to exercise the joints within a few days of the operation. Additional measures such as pre-operative surgery for infection or distraction of shortening were used in some cases.

3. The pseudarthrosis healed in all cases, even when infection was present. The nails were generally not removed until after healing had occurred.

4. It is concluded that the Küntscher method gives remarkably rapid consolidation and restoration of function even in difficult cases of non-union of shaft fracture, particularly of the femur.

\section{REFERENCES}

BöHLER, J. (1966): Treatment of Non-union of the Tibia with Closed and Semiclosed Intramedullary Nailing. Clinical Orthopaedics and Related Research, 43, 93.

Boyd, H. B., Anderson, L. D., and Johnston, D. S. (1966): Changing Concepts in the Treatment of Nonunion. Clinical Orthopaedics and Related Research, 43, 37.

Christensen, N. O. (1970): Shortening in Pseudarthrosis. Treatment with the Küntscher Distractor. Acta orthopaedica Scandinavica, 41, 363.

DanCKWARDt-Lillieström, G. (1969): Reaming of the Medullary Cavity and its Effect on Diaphyseal Bone. Acta orthopaedica Scandinavica, Supplement 128.

Fischer, S. (1965): Die Marknagelung. Chirurg, 36, 558.

KoslowsKı, L., and Weller, S. (1962): Tücken der Marknagelung. Chirurg, 33, 460.

KünTSCHER, G. (1967): Practice of Intramedullary Nailing. Translated by H. H. Rinne. Springfield, Illinois: Charles C. Thomas.

LAURENT, L. E., and LANGenskiöLd, A. (1967): Osteosynthesis with a Thick Medullary Nail in Non-union of Long Bones. Acta orthopaedica Scandinavica, 38, 341.

Maurath, J., and Christ, H. (1963): Untersuchungen über die Stabilität bei der Osteosynthese von Shaftfrakturen mit dem Küntschernagel. Archiv für orthopädische und Unfall-Chirurgie, 55, 422.

Macausland, W. R., Jun., and Eaton, R. G. (1963): The Management of Sepsis following Intramedullary Fixation for Fractures of the Femur. Journal of Bone and Joint Surgery, 45-A, 1643.

Müller, M. E., Allgöwer, M., and Willenegger, H. (1965): Technique of Internal Fixation of Fractures. Berlin-Heidelberg-New York: Springer Verlag.

Müller, M. E. (1966): Treatment of Nonunions by Compression. Clinical Orthopaedics and Related Research, 43, 83.

Palmer, I. (1951): On Complications and Technical Problems of Medullary Nailing. Acta chirurgica Scandinavica, 101, 484. 